\title{
Application of Multivariate Techniques in Horticulture Research-a Case Study of Apple Crop
}

\author{
Anju Sharma ${ }^{1 *}$, P. K. Mahajan ${ }^{1}$, R. Malhotra ${ }^{2}$, O. K. Belwal ${ }^{3}$ and Satish K. Sharma ${ }^{1}$ \\ ${ }^{1}$ Dr. Y. S. Parmar University of Horticulture and Forestry, Nauni, Solan, H.P. (173 230), India \\ ${ }^{2}$ National Dairy Research Institute, Karnal, Haryana (132 001), India \\ ${ }^{3} \mathrm{HNB}$ Garhwal (Central University), Srinagar, Garhwal, Uttarakhand (246 174), India
}

\section{Corresponding Author}

Anju Sharma

e-mail: anjusharma_uhf@yahoo.com

\author{
Article History \\ Article ID: AR1884 \\ Received in $06^{\text {th }}$ July, 2018 \\ Received in revised form $13^{\text {th }}$ September, 2018 \\ Accepted in final form $20^{\text {th }}$ September, 2018
}

\begin{abstract}
The present study deals with the usefulness of Principal Component Analysis and Factor Analysis for determining the relative contribution of morphological characters responsible in increasing the apple productivity. The three different apple producing locations of Himachal Pradesh, viz., Shimla, Kotkhai, and Theog were considered for the study. Four of the thirteen principal components explained around $75.40,86.58$ and $89.40 \%$ of the total variation at Shimla, Kotkhai and Theog locations, respectively. The first principal component may be interpreted as Plant Vigour and Yield Component. The second component may be termed as Volume and Spurs of Plant and Yield component, while Fruitfulness and Size of Tree may be regarded as the third principal component. Factor analysis grouped the thirteen morphological characters into three main factors. At Shimla location, the first factor (Plant vigour and yield), the second factor (Fruitfulness) and the third factor (Size of Tree and Fruit) explained 37.55\%, 21.43\% and 9.33\% of the total variation, respectively. At Kotkhai location, $55.01 \%, 17.37 \%$ and $7.92 \%$ of total variation was explained by the Plant Vigour and Plant Growth (first factor), Fruitfulness (second factor) and Yield and Plant Vigour (third factor) characters, respectively. Factor analysis of Theog location showed that the first factor i.e. Plant Vigour, second factor i.e. Fruitfulness and the third factor i.e. Yield and Plant Growth explained $60.00 \%, 13.14 \%$ and $9.44 \%$ of the total variation, respectively. Total variance explained collectively by three factors was observed to be $68.31 \%, 80.29 \%$, and $82.58 \%$ at Shimla, Kotkhai and Theog locations respectively.
\end{abstract}

Keywords: Apple, factor analysis, principal component analysis

\section{Introduction}

Apple is the most dominating fruit crop in Himachal Pradesh. It accounts for $49 \%$ of the total area under fruit crops $(2,29,202$ hectares) and more than $76 \%$ of the total fruit production $(6,11,877 \mathrm{MT})$ of the State. The area under apple and its production has increased from 88,673 hectares and 49,129 tones MT in 1999-00 to 1,11,896 ha and 4,68,134 MT in 201617 (Anonymous, 2017), respectively. Apple cultivation has completely transformed the socio-economic status of rural masses in the High Hills zone of the State.

An attempt to study a series of univariate statistical analyses carried out for each variable is, in general, not adequate as it ignores the inter correlation among the variables influencing apple yield. On the other hand multivariate methods allow the simultaneous analysis of a dataset for exploring its overall structure, for measuring redundancy in the measurements, for studying the interdependence and relative importance of various characters involved, for summarizing the salient features of the study, for forming groups' common characteristics to provide more meaningful information.
Under the present study, in order to reduce the redundancy, principal component analysis was employed to reduce the observed variables into a number of principal components that accounted for most of the variance in the observed variables and most important components were extracted for interpreting the result. Generally, the factors corresponding to eigen values less than one are not considered as per Gutman's lower bound principal (Kaiser, 1958). However, another methodology include the amount of total variance explained (i.e. $>80 \%$ ) by the principle components (Johnson and Wichern, 1992). An attempt has been made for the assessment of relative contribution of morphological characters responsible in increasing the apple productivity in Himachal Pradesh through factor analysis by decreasing the volume of data and getting results of the data which showed a high correlation among the primary variables by reducing a large number of correlated variables to a small number of uncorrelated variables or factors. Factor analysis was carried out to analyse interrelationships among a large number of variables (inter correlation) and to explain these variables in terms of their common underlying dimensions or 
factors (Kendall, 1968). A large number of variables are often measured by plant breeders, some of which may not be of sufficient discriminatory power for germplasm evaluation, characterization and management (Maji and Shaibu, 2012). In such case, principal component analysis (PCA) may be used to reveal patterns and eliminate redundancy in data sets (Amy and Pritts, 1991) as morphological and physiological variations routinely occur in crop species. Principal component analysis has been successfully used to aid in crop improvement strategies (Placide et al., 2015; Das et al., 2017). Similar studies were carried out estimate relationships between plant characters and yield components of 41 native melons (Rad et al., 2014). The factor analysis results revealed that six factors could explain approximately $77 \%$ of total variation; those factors were strongly influenced by number of seed per fruit, thousands seed weight, fruit width, number of days to flowering, fruit length, number of days to fruit ripening and seed width. Fahim (2014) used PCA to study 57 promising genotypes and lines of bread wheat based on yield and some agronomic traits. First component with the special value of 1.6 justifies more than $40 \%$ and the second component with special value of 0.98 justifies more than $24 \%$ of changes. Kamran et al. (2016) conducted a study to differentiate the varieties of wheat depending on their morphological traits relating to yield and to estimate those factors which are responsible for the highest yield plant ${ }^{-1}$. Factors examination exposed 5 essential factors that estimated $73.24 \%$ of the total differences, depending on principal component processes. Verma et al. (2018) studied the relative contribution of morphological and reproductive characters responsible in increasing the yield of kinnow in Indpur block of district
Kangra of Himachal Pradesh, using discriminant and principal component analysis.

\section{Materials and Methods}

Data were recorded on different tree growth (morphological) characteristics viz., $X_{1}=$ Age (years), $X_{2}=$ Girth $(m), X_{3}=$ Height $(\mathrm{m}), X_{4}=\operatorname{Spread}(\mathrm{m}), X_{5}=$ Volume $\left(\mathrm{m}^{3}\right), X_{6}=$ No. of main branches, $X_{7}=$ Number of secondary branches, $X_{8}=$ No. of spurs/tertiary branch, $X_{9}=$ Length of spurs $(\mathrm{cm}), X_{10}=$ Number of flowers/ tertiary branch, $X_{11}=$ Number of fruits/tertiary branch, $\mathrm{X}_{12}=$ Fruit weight $(\mathrm{g})$ and $\mathrm{X}_{13}=$ Yield of tree $(\mathrm{kg})$ at three different apple growing locations of Himachal Pradesh, viz., Shimla, Kotkhai and Theog from a random sample of 300 apple trees from a randomly selected orchard at each location.

The data collected location wise were subjected to principal component analysis and factor analysis using SAS software (2004).

\section{Results and Discussion}

\subsection{Principal component analysis}

The principal component analysis was carried out separately for three locations under study and the results have been presented in Tables 1 and 2. Table 1 clearly showed that three of thirteen variables had eigenvalue greater than one and as such these were playing the main role in the analysis. The fourth variable, whose eigenvalue was very close to one, had also been included. Thus, four principal components have been retained in the analysis which explained around $75.40,86.58$ and $89.40 \%$ of the total variation at Shimla, Kotkhai and Theog locations, respectively. At Shimla location,

Table 1: Eigenvalues of the correlation matrix

\begin{tabular}{|c|c|c|c|c|c|c|c|c|c|c|c|c|}
\hline \multirow[t]{2}{*}{ Variables } & \multicolumn{4}{|c|}{ Shimla } & \multicolumn{4}{|c|}{ Kotkhai } & \multicolumn{4}{|c|}{ Theog } \\
\hline & EV & PV & $\mathrm{CV}$ & $C: E$ & EV & PV & $\mathrm{CV}$ & C:E & EV & PV & $\mathrm{CV}$ & $C: E$ \\
\hline Age $\left(X_{1}\right)$ & 4.882 & 37.55 & 37.55 & 0.672 & 7.151 & 55.01 & 55.01 & 0.599 & 7.800 & 60.00 & 60.00 & 0.924 \\
\hline Girth $\left(X_{2}\right)$ & 2.785 & 21.43 & 58.98 & 0.758 & 2.258 & 17.37 & 72.38 & 0.876 & 1.708 & 13.14 & 73.14 & 0.955 \\
\hline Height $\left(X_{3}\right)$ & 1.213 & 9.33 & 68.31 & 0.545 & 1.029 & 7.92 & 80.29 & 0.870 & 1.227 & 9.44 & 82.58 & 0.930 \\
\hline Spread $\left(X_{4}\right)$ & 0.923 & 7.10 & 75.40 & 0.873 & 0.817 & 6.28 & 86.58 & 0.825 & 0.886 & 6.82 & 89.40 & 0.961 \\
\hline Volume $\left(X_{5}\right)$ & 0.780 & 6.00 & 81.40 & 0.867 & 0.576 & 4.43 & 91.01 & 0.860 & 0.815 & 6.27 & 95.67 & 0.903 \\
\hline $\begin{array}{l}\text { No. of main branches } \\
\left(X_{6}\right)\end{array}$ & 0.749 & 5.76 & 87.16 & 0.629 & 0.474 & 3.64 & 94.65 & 0.533 & 0.303 & 2.33 & 98.00 & 0.481 \\
\hline $\begin{array}{l}\text { No. of secondary } \\
\text { branches }\left(X_{7}\right)\end{array}$ & 0.537 & 4.13 & 91.29 & 0.423 & 0.285 & 2.19 & 96.85 & 0.766 & 0.131 & 1.01 & 99.00 & 0.835 \\
\hline No. of spurs $\left(X_{8}\right)$ & 0.381 & 2.93 & 94.22 & 0.937 & 0.146 & 1.12 & 97.97 & 0.972 & 0.060 & 0.46 & 99.47 & 0.994 \\
\hline Length of spurs $\left(X_{g}\right)$ & 0.359 & 2.76 & 96.98 & 0.487 & 0.133 & 1.02 & 98.99 & 0.636 & 0.028 & 0.21 & 99.68 & 0.475 \\
\hline No. of flowers $\left(X_{10}\right)$ & 0.222 & 1.71 & 98.69 & 0.925 & 0.077 & 0.59 & 99.58 & 0.972 & 0.020 & 0.16 & 99.84 & 0.994 \\
\hline No. of fruits $\left(X_{11}\right)$ & 0.111 & 0.85 & 99.54 & 0.794 & 0.052 & 0.40 & 99.98 & 0.971 & 0.014 & 0.11 & 99.95 & 0.998 \\
\hline Fruit weight $\left(\mathrm{X}_{12}\right)$ & 0.042 & 0.33 & 99.87 & 0.493 & 0.003 & 0.02 & 100.00 & 0.750 & 0.007 & 0.05 & 100.00 & 0.355 \\
\hline Yield $\left(X_{13}\right)$ & 0.017 & 0.13 & 100.00 & 0.482 & 0.000 & 0.00 & 100.00 & 0.808 & 0.000 & 0.00 & 100.00 & 0.940 \\
\hline
\end{tabular}

EV: Eigen value ( $\lambda$ ); PV: \% or proportion of Variance; CV: Cumulative \% of variance; C:E: Communalities: Extraction 
International Journal of Bio-resource and Stress Management 2018, 9(5):556-561

\begin{tabular}{|c|c|c|c|c|c|c|c|c|c|c|c|c|}
\hline \multirow[t]{2}{*}{ Variables } & \multicolumn{4}{|c|}{ Shimla } & \multicolumn{4}{|c|}{ Kotkhai } & \multicolumn{4}{|c|}{ Theog } \\
\hline & PC1 & PC2 & PC3 & PC4 & PC1 & PC2 & PC3 & PC4 & PC1 & PC2 & PC3 & PC4 \\
\hline Age $\left(X_{1}\right)$ & 0.366 & -0.076 & -0.044 & -0.024 & 0.268 & -0.098 & 0.252 & -0.309 & 0.336 & -0.150 & 0.054 & 0.006 \\
\hline Girth $\left(X_{2}\right)$ & 0.383 & -0.060 & -0.167 & 0.038 & 0.348 & -0.066 & -0.014 & -0.141 & 0.336 & -0.208 & -0.038 & 0.012 \\
\hline Height $\left(X_{3}\right)$ & 0.302 & -0.189 & 0.030 & 0.300 & 0.255 & -0.410 & 0.159 & -0.204 & 0.299 & -0.371 & 0.009 & -0.060 \\
\hline Spread $\left(X_{4}\right)$ & 0.418 & -0.048 & -0.099 & -0.040 & 0.299 & -0.284 & -0.040 & -0.079 & 0.348 & -0.104 & 0.006 & 0.000 \\
\hline Volume $\left(\mathrm{X}_{5}\right)$ & 0.405 & -0.094 & -0.185 & 0.022 & 0.310 & -0.275 & -0.009 & -0.077 & 0.291 & -0.377 & 0.019 & -0.087 \\
\hline $\begin{array}{l}\text { No. of main branch- } \\
\text { es }\left(X_{6}\right)\end{array}$ & 0.335 & -0.017 & -0.254 & -0.158 & 0.211 & 0.036 & -0.454 & 0.611 & 0.095 & 0.139 & 0.554 & -0.187 \\
\hline $\begin{array}{l}\text { No. of secondary } \\
\text { branches }\left(X_{7}\right)\end{array}$ & 0.052 & -0.242 & 0.447 & 0.697 & 0.319 & -0.069 & -0.157 & 0.066 & 0.320 & -0.032 & 0.169 & -0.002 \\
\hline No. of spurs $\left(X_{8}\right)$ & 0.158 & 0.531 & 0.155 & 0.001 & 0.258 & 0.468 & 0.028 & -0.141 & 0.282 & 0.443 & -0.173 & 0.013 \\
\hline Length of spurs $\left(X_{9}\right)$ & 0.062 & -0.221 & 0.521 & -0.590 & 0.297 & 0.014 & -0.063 & 0.289 & -0.008 & -0.205 & -0.572 & 0.521 \\
\hline No. of flowers $\left(X_{10}\right)$ & 0.142 & 0.533 & 0.174 & 0.019 & 0.258 & 0.468 & 0.028 & -0.141 & 0.282 & 0.444 & -0.172 & 0.012 \\
\hline No. of fruits $\left(X_{11}\right)$ & 0.091 & 0.518 & 0.074 & 0.153 & 0.265 & 0.455 & 0.041 & -0.133 & 0.289 & 0.427 & -0.143 & 0.024 \\
\hline Fruit weight $\left(\mathrm{X}_{12}\right)$ & 0.178 & -0.042 & 0.527 & -0.056 & 0.093 & 0.036 & 0.816 & 0.534 & 0.078 & 0.071 & 0.495 & 0.824 \\
\hline Yield $\left(\mathrm{X}_{13}\right)$ & 0.292 & -0.005 & 0.228 & -0.144 & 0.331 & -0.095 & -0.075 & 0.164 & 0.346 & -0.021 & -0.078 & -0.053 \\
\hline
\end{tabular}

the first, second and third components with 4.882, 2.785 and 1.213 eigen values justified $37.55,21.43$ and $9.33 \%$ of variation, respectively. The first component extracted in a principal component analysis accounted for a maximal amount of total variance in the observed variables and showed relatively maximum weight of Spread $\left(X_{4}=0.418\right)$ followed by Volume $\left(X_{5}=0.405\right)$, Girth $\left(X_{2}=0.383\right)$, Age $\left(X_{1}=0.366\right)$, and Number of main branches $\left(X_{6}=0.335\right)$ respectively (Table 2 ). Under typical conditions this means that the first component was correlated with atleast some of observed variables. This component may be interpreted as Plant Vigour. The second principal component was dominated by Number of flowers $\left(X_{10}=0.533\right)$, Number of spurs $\left(X_{8}=0.531\right)$ and Number of fruits $\left(X_{11}=0.518\right)$. The rest of the variables gave negative values and hence negative contribution. Number of flowers and Number of spurs represent Volume and Spurs of Plant while the Number of fruits represents the Yield Component. In the third component, Fruit weight $\left(X_{12}=0.527\right)$, Length of spurs $\left(X_{9}=0.521\right)$ and Number of secondary branches $\left(X_{7}=0.447\right)$ had higher weight than other variables. The variables viz., Age $\left(X_{1}\right)$, Girth $\left(X_{2}\right)$, Spread $\left(X_{4}\right)$, Volume $\left(X_{5}\right)$, and Number of main branches $\left(X_{6}\right)$ contributed negatively. Thus, the third principal component falls into two groups. In the first group high values for Fruit weight can be interpreted as Fruitfulness of Plant and the second group consisting of Length of spurs and Number of secondary branches can be termed as Plant Growth. The fourth component was the combination of Number of secondary branches, Height representing Size of Tree, and Number of fruits interpreting Yield Component. Similarly, in Kotkahi location, the variables loading (Table 2) for first principal component was highest for Girth $\left(X_{2}=0.348\right)$, Yield $\left(X_{13}=0.331\right)$, Number of secondary branches $\left(X_{6}=0.319\right)$, and Volume $\left(X_{5}=0.310\right)$. This can be categorized into two categories of Plant Vigour consisting of Girth, Number of secondary branches and Volume and Yield Component consisting of Yield. The second principal component had high values for Number of spurs, Number of flowers and Number of fruits and may be interpreted as Fruitfulness. The third component was a combination of variables viz., Fruit weight, Age, and Height. It can again be put into two groups viz., the first group comprising of Fruit weight as Yield Component and the second group being combination of Age and Height of the tree as Plant Growth. Being dominated by variables like Number of main branches, Fruit weight, and Length of spurs, the fourth component may be interpreted as Plant Vigour, Plant Size, Spurs of Plant and Yield Component. The PC1, PC2, PC3 and PC4 showed relatively large variation with eigen values $7.151,2.258,1.029$ and 0.817 respectively (Table 1). The eigen values greater than one represented exact linear dependency. While in Theog location the eigen values of PC1, PC2, PC3 and PC4 were 7.800,1.708,1.227 and 0.886 explain $60.00,13.14,9.44$, and $6.82 \%$ of variance, respectively (Table 1). The variables loading for first principal component were highest for Spread, Yield, Girth, and Age. This component may be interpreted as Plant Vigour and Yield Component (Table 2). The second principal component was dominated by Number of flowers, No. of spurs and No. of fruits. No. of flowers and No. of spurs represents Volume and spurs of Plant while the Number of fruits represents the Yield Component. The third principal component falls into two groups. In the first group high values for fruit weight can be interpreted as fruitfulness of plant and the second group consisting of no. of main branches, no. of secondary branches and Length of spurs and can be referred as size of tree and plant growth. 
The fourth component was the combination of fruit weight, length of spurs and no. of fruits interpreting mainly the yield Component.

lezzoni and Pritts (1991) applied PCA in horticultural research. The response of groups of variables or complex traits to imposed treatments or evolutionary pressures can be quantified and tested using a combination of PCA and simple univariate statistics. The same responses of groups could be used successfully to develop novel hypotheses. It was now possible to apply different treatments to increase yield and determine whether the yield increase was the result of an increase in vegetative vigour, a change in the balance of vegetative growth and fruit production, a reduction in fruit set or a combination of these factors.

\subsection{Factor analysis}

Factor analysis was carried out separately for three study locations. Three factors have been retained by Mineigen criterion in all the locations (Table 3 ). While considering the factors and describing the relative contribution of each variable or character, the signs and relative magnitude makes a difference rather than the absolute values of the coefficients. The factors having eigenvalue greater than one were to be retained.

Total variance explained by three factors was found to be 68.31, 80.29 and $82.58 \%$ at Shimla, Kotkhai and Theog locations respectively (Table 3 ). The variance of first, second and third factor was found to be 4.882 (37.55\% of total), 2.785 (21.43\% of total) and 1.213 (9.33\% of total) respectively at Shimla location. As per eigenvalues pertaining to Kotkhai, three factors were found to be contributing the variance of order of $55.01,17.37$ and $7.92 \%$ of total variation respectively. Similarly, the eigenvalues of first, second and third factors were $7.800,1.708$, and 1.227 respectively in Theog location. The corresponding variances contributed to 60.00, 13.14, and $9.44 \%$ of total variance, respectively. Ignoring the non-

\begin{tabular}{|c|c|c|c|c|c|c|c|c|c|c|c|c|}
\hline \multirow[t]{2}{*}{ Variables } & \multicolumn{4}{|c|}{ Shimla } & \multicolumn{4}{|c|}{ Kotkhai } & \multicolumn{4}{|c|}{ Theog } \\
\hline & $\begin{array}{l}\text { Fac- } \\
\text { tor } 1\end{array}$ & $\begin{array}{l}\text { Factor } \\
2\end{array}$ & $\begin{array}{l}\text { Factor } \\
3\end{array}$ & FCE & $\begin{array}{c}\text { Factor } \\
1\end{array}$ & $\begin{array}{c}\text { Factor } \\
2\end{array}$ & $\begin{array}{c}\text { Factor } \\
3\end{array}$ & FCE & $\begin{array}{c}\text { Factor } \\
1\end{array}$ & $\begin{array}{c}\text { Factor } \\
2\end{array}$ & $\begin{array}{c}\text { Factor } \\
3\end{array}$ & FCE \\
\hline Age $\left(X_{1}\right)$ & 0.809 & -0.126 & -0.048 & 0.673 & 0.716 & -0.147 & 0.255 & 0.599 & 0.939 & -0.196 & 0.060 & 0.924 \\
\hline Girth $\left(X_{2}\right)$ & 0.846 & -0.099 & -0.183 & 0.759 & 0.931 & -0.099 & -0.014 & 0.876 & 0.938 & -0.272 & -0.042 & 0.955 \\
\hline Height $\left(X_{3}\right)$ & 0.667 & -0.315 & 0.033 & 0.545 & 0.681 & -0.617 & 0.161 & 0.870 & 0.834 & -0.484 & 0.010 & 0.930 \\
\hline Spread $\left(\mathrm{X}_{4}\right)$ & 0.924 & -0.080 & -0.109 & 0.873 & 0.801 & -0.427 & -0.041 & 0.825 & 0.971 & -0.135 & 0.006 & 0.961 \\
\hline Volume $\left(X_{5}\right)$ & 0.895 & -0.156 & -0.203 & 0.867 & 0.830 & -0.413 & -0.010 & 0.860 & 0.812 & -0.493 & 0.021 & 0.903 \\
\hline $\begin{array}{l}\text { No. of main branches } \\
\left(\mathrm{X}_{6}\right)\end{array}$ & 0.740 & -0.028 & -0.280 & 0.627 & 0.564 & 0.054 & -0.461 & 0.533 & 0.264 & 0.181 & 0.614 & 0.480 \\
\hline $\begin{array}{l}\text { No. of secondary } \\
\text { branches }\left(X_{7}\right)\end{array}$ & 0.115 & -0.404 & 0.492 & 0.419 & 0.854 & -0.104 & -0.160 & 0.766 & 0.893 & -0.042 & 0.188 & 0.835 \\
\hline No. of spurs $\left(X_{8}\right)$ & 0.349 & 0.887 & 0.171 & 0.938 & 0.691 & 0.703 & 0.029 & 0.972 & 0.788 & 0.579 & -0.191 & 0.994 \\
\hline Length of spurs $\left(X_{9}\right)$ & 0.138 & -0.369 & 0.574 & 0.485 & 0.795 & 0.022 & -0.064 & 0.636 & -0.023 & -0.267 & -0.634 & 0.474 \\
\hline No. of flowers $\left(X_{10}\right)$ & 0.313 & 0.889 & 0.192 & 0.925 & 0.691 & 0.703 & 0.029 & 0.972 & 0.788 & 0.580 & -0.191 & 0.994 \\
\hline No. of fruits $\left(X_{11}\right)$ & 0.201 & 0.864 & 0.081 & 0.794 & 0.708 & 0.684 & 0.041 & 0.971 & 0.807 & 0.559 & -0.158 & 0.988 \\
\hline Fruit weight $\left(\mathrm{X}_{12}\right)$ & 0.393 & -0.071 & 0.580 & 0.496 & 0.249 & 0.054 & 0.828 & 0.750 & 0.218 & 0.093 & 0.549 & 0.357 \\
\hline Yield $\left(\mathrm{X}_{13}\right)$ & 0.646 & -0.009 & 0.251 & 0.481 & 0.884 & -0.143 & -0.076 & 0.808 & 0.966 & -0.027 & -0.086 & 0.941 \\
\hline Eigenvalues & 4.882 & 2.785 & 1.213 & & 7.151 & 2.258 & 1.029 & & 7.800 & 1.708 & 1.227 & \\
\hline$\%$ of variance & 37.55 & 21.43 & 9.33 & & 55.01 & 17.37 & 7.92 & & 60.00 & 13.14 & 9.44 & \\
\hline $\begin{array}{l}\text { Cumulative } \% \text { of vari- } \\
\text { ance }\end{array}$ & 37.55 & 58.98 & 68.31 & & 55.01 & 72.38 & 80.29 & & 60.00 & 73.14 & 82.58 & \\
\hline Location & \multicolumn{7}{|c|}{ Equations in terms of factors } & \multicolumn{5}{|c|}{ Communality } \\
\hline Shimla & \multicolumn{7}{|c|}{$\mathrm{X}_{8}=0.349 \mathrm{~F}_{1}+0.887 \mathrm{~F}_{2}+0.171 \mathrm{~F}_{3}$} & \multicolumn{5}{|c|}{0.938} \\
\hline Kotkhai & \multicolumn{7}{|c|}{$X_{10}=0.691 F_{1}+0.703 F_{2}+0.029 F_{3}$} & \multicolumn{5}{|c|}{0.972} \\
\hline Theog & \multicolumn{6}{|c|}{$\mathrm{X}_{10}=0.788 \mathrm{~F}_{1}+0.580 \mathrm{~F}_{2}-0.191 \mathrm{~F}_{3}$} & & \multicolumn{5}{|c|}{0.994} \\
\hline
\end{tabular}

FCE: Final Communality Estimates; Total of final communality estimates: Shimla: 8.880 ; Kotkhai: 10.438; Theog: 10.735 
significant correlations, the orthogonal factors extracted can be expressed as follows:

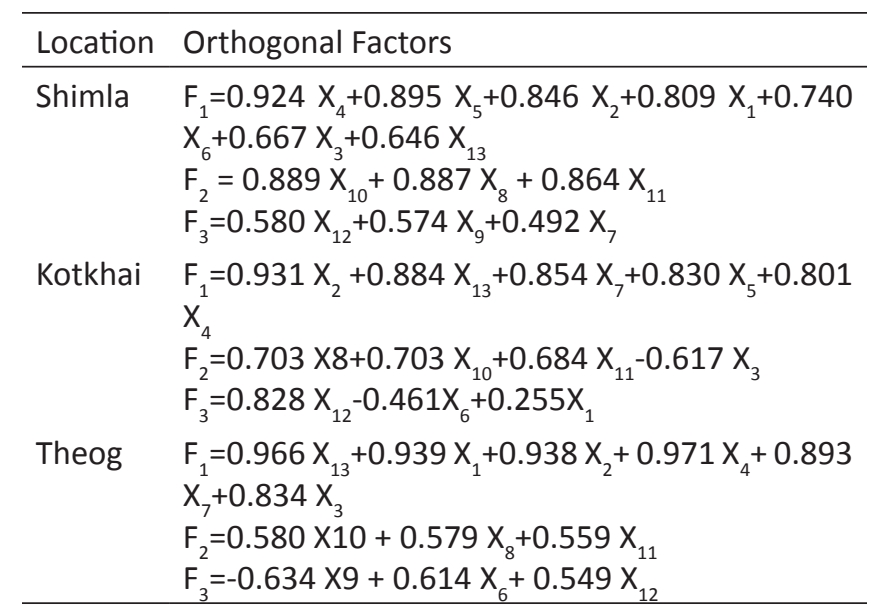

At Shimla location, ignoring the relatively low weighing characters, the first factor being a combination of number of variables viz., Spread $\left(X_{4}\right)$, Volume $\left(X_{5}\right)$, Girth $\left(X_{2}\right)$, Age $\left(X_{1}\right)$, no. of main branches $\left(X_{6}\right)$, Height $\left(X_{3}\right)$, and Yield $\left(X_{13}\right)$ represented the Plant Vigour, which indicates the general health of the plant. Yield also plays the significant role in representing the first factor. The second factor was a combination of Number of flowers $\left(X_{10}\right)$, Number of spurs $\left(X_{8}\right)$ and Number of fruits $\left(\mathrm{X}_{11}\right)$ and depicted the Yield Factor or the Fruitfulness/Fruiting. The third factor signifies Size of Tree and Fruit and was a combination of Fruit weight $\left(X_{12}\right)$, Length of spurs $\left(X_{9}\right)$, and Number of secondary branches $\left(X_{7}\right)$. In Kotkhai population, first factor was a combination of Girth $\left(X_{2}\right)$, Yield $\left(X_{13}\right)$, Number of secondary branches $\left(X_{7}\right)$, Volume $\left(X_{5}\right)$ and Spread $\left(X_{4}\right)$ of the tree. Thus, variable loading on this factor falls largely into two groups. First group may be interpreted as Plant Vigour and Plant Growth consisting of $\mathrm{X}_{2}, \mathrm{X}_{7}, \mathrm{X}_{5}$, and $\mathrm{X}_{4}$, while the second group has a Yield factor. The second factor represented the yield factor or the fruitfulness / fruiting being a combination of no. of spurs $\left(X_{8}\right)$, no. of flowers $\left(X_{10}\right)$ and no. of fruits $\left(X_{11}\right)$. The third factor signifies Yield factor and plant vigour. It was a combination of fruit weight $\left(X_{12}\right)$, no. of main branches $\left(X_{6}\right)$ and age $\left(X_{1}\right)$. The variables no. of spurs $\left(X_{8}\right)$, no. of flowers $\left(X_{10}\right)$, no. of fruits $\left(X_{11}\right)$, Girth $\left(X_{2}\right)$, height $\left(X_{3}\right)$, volume $\left(X_{5}\right)$ and spread $\left(X_{4}\right)$, possessed the communalities of higher order.

Ignoring the relatively low weighing characters, in case of Theog location, the first factor was a combination of number of variables viz., Yield $\left(X_{13}\right)$, Age $\left(X_{1}\right)$, Girth $\left(X_{2}\right)$, Spread $\left(X_{4}\right)$, Number of secondary branches $\left(X_{7}\right)$, and Height $\left(X_{3}\right)$ and signifies the plant vigour, which indicates the general health of the plant. Yield also plays the significant role in representing the first factor. The second factor was a combination of Number of flowers $\left(X_{10}\right)$, no. of spurs $\left(X_{8}\right)$ and no. of fruits $\left(X_{11}\right)$, signifies the yield factor or the fruitfulness/fruiting. The third factor signifies yield factor and plant growth. It was a combination of length of spurs $\left(X_{9}\right)$, Number of main branches $\left(\mathrm{X}_{6}\right)$ and fruit weight $\left(\mathrm{X}_{12}\right)$. All thirteen characters can be expressed in terms of these identified three factors. For example,

Factor Analysis has been used by different workers in different fields. El-Geddawi et al. (1992) used factor analysis to determine the dependence structure of cane yield through some morphological and chemical traits. They pointed out that factor analysis divided the studied traits into four groups accounting for $76.88 \%$ of the total variability in the dependence structure. The first factor contained the chemical characters that were most contributing in sugar yield. Factor analysis based on principal component analysis method and varimax rotation of morphological traits in potato indicated that three important factors accounted for about $80.05 \%$ of the total variation among traits (Felenji et al., 2011). The first factor assigned $33.29 \%$ of total variation between traits and was significantly related with tuber yield. Therefore, this factor was regarded as tuber yield factor. Other factors accounted for 30.48 and $16.28 \%$ of variation between traits and were entitled as stolon length factor and negative factor for diagonal height, respectively. Siahbidi et al. (2012) studied and classified agro-morphological characters in lines of durum wheat using factor analysis. The first factor assigned 35.13\% of total variation between characters and was significantly related with yield. Therefore, this factor was regarded as yield and yield component factor.

\section{Conclusion}

The multivariate analysis, being an important tool in explanatory work, has brought out some basic factors associated with morphological characters of apple and can help to determine the nature and sequence of traits to be selected to speed up the breeding programme. The first principal component and the first factor consisting of Spread, girth, height and yield of tree variables may be interpreted as plant vigour and yield component or factor, is responsible for higher apple productivity.

\section{Reference}

Amy, E.L., Pritts, M.P., 1991. Application of principal component analysis to horticultural research. Horticultural Science 26(4), 334-338.

Anonymous, 2017. Directorate of Horticulture, Shimla, Himachal Pradesh, India.

Das, S., Das, S.S., Chakraborty, I., Roy, N., Nath, M.K., Sarma, D., 2017. Principal component analysis in plant breeding. Biomolecule Reports- an International eNewsletter BR/09/17/03.

El-Geddawi, I.H., Nasr, S.M., Abo-Douh, A.M., 1992. Factor analysis of yield components of sugarcane. Pakistan Sugar Journal 6(3), 11-14.

Fahim, M.G., 2014. Study on yield and some agronomic traits of promising genotypes and lines of bread wheat through principal component analysis. Journal of Biodiversity and Environmental Sciences 4(2), 443-446. 
Felenji, H., Aharizad, S., Afsharmanesh, G.R., Ahmadizadeh, M., 2011. Evaluating correlation and factor analysis of morphological traits in potato cultivars in fall cultivation of Jiroft area. American-Eurasian Journal of Agricultural \& Environmental Science 11 (5), 679-684.

lezzoni, A.F., Pritts, M.P., 1991. Applications of principal component analysis to horticultural research. Horticultural Science 26(4), 334-338.

Johnson, R.A., Wichern, D.W., 1992. Applied multivariate statistical analysis.PrenticeHall, Inc.

Kaiser, H.F., 1958. The varimax criterion for analystic rotation in factor analysis. Psychometrika 23, 187-200.

Kamran, M., Inamullah, Iqbal, M.S., 2016. Yield performance and factor analysis for superior cultivars identification in wheat (Triticum aestivum L.). PSM Biological Research 01(1), 11-15.

Kendall, M.G., 1968. A course in Multivariate Analysis. Charles Griffin Co. Limited, London, 184.

Maji, A.T., Shaibu, A.A., 2012. Application of principal component analysis for rice germplasm characterization and evaluation. Journal of Plant Breeding and Crop
Science 4(6), 87-93.

Placide, R., Shimelis H., Mark Laing, M., Gahakwa, D., 2015. Application of principal component analysis to yield and yield related traits to identify sweet potato breeding parents. Journal of Tropical Agriculture 92(1), 1-15.

Rad, M.R.N., Koohkan, S., Fanaei, H.R., Khajedad, M., 2014. Multivariate analysis to determine relationship between phenological traits with yield components in native melon population (Cucumis melo L.). Scientific Journal of Crop Science 3(5), 48-55.

SAS, 2004. SAS software. SAS Institute Inc., Cary, NC, USA.

Siahbidi, M.M.P., Aboughadareh, A.P., Tahmasebi, G.R., Seyedi, A. , Jasemi, M., 2012. Factor analysis of agromorphological characters in durum wheat (Triticum durum Desf.) lines. International Journal of Agriculture and Crop Sciences 4(23), 1758-1762.

Verma, G., Sharma, A., Mahajan, P.K., 2018. Study on yield and some morphological characters for optimizing kinnow yield through multivariate statistical techniques. International Journal of Farm Sciences 8(2), 162-165. 